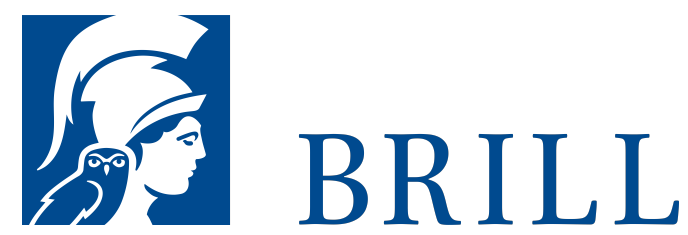

\title{
Werke und Wirkmacht
}

Morphomatische Reflexionen zu archäologischen Fallstudien

\section{Author: Dietrich Boschung}

Die Texte dieses Bandes legen ausgehend von griechischen und römischen Kunstwerken dar, wie Leistungen des menschlichen Intellekts eine konkret erlebbare Form erhalten haben und welche Wirkmacht sie gerade durch die Ausgestaltung entfalten konnten.

Antike Artefakte wie Statuen, Reliefs oder Gemälde gaben Vorstellungen und Wissen eine sinnlich erfahrbare Form, machten sie anschaulich, überzeugend und dauerhaft. Zugleich veränderten sie intellektuelle Leistungen, indem sie bestimmte Aspekte betonten, präzisierten oder neu kombinierten, andere aber reduzierten oder ganz wegließen. Das Buch untersucht ihre Entstehung, die medialen Bedingungen der Gestaltungsprozesse und die Auswirkungen der gewordenen Form. Es legt den dafür entwickelten methodischen Ansatz des Internationalen Kollegs Morphomata dar und verbindet Fallstudien aus der Klassischen Archäologie mit Überlegungen zu zentralen Aspekten der materiellen Kultur.



Pages: 503

Seiten, $280 \mathrm{~s} / \mathrm{w}$ und 14 farb. Abb. Language:

German

Subjects: Art

History, Art

History

Publisher: Brill |

Fink

Series:

Morphomata,

Volume: 36

Paperback

Publication date:

14 Jul 2017

ISBN: 978-3-

7705-6282-4

List price

USD $\$ 120.00$ 
Dietrich Boschung (Klassische Archäologie), Professor an der Universität zu Köln, Direktor des Internationalen Kollegs Morphomata. Zuletzt erschienen: Archäologie als Kunst: Archäologische Objekte und Verfahren in der bildenden Kunst des 18. Jh.s und der Gegenwart. Morphomata 30, Paderborn 2015. - Zus. mit K.-J. Hölkeskamp und Cl. Sode (Hrsg.), Raum und Performanz - Rituale in Residenzen. Stuttgart 2015.

For more information see brill.com

Order information: Order online at brill.com +44330 3330049 | customerservices@brill.com Submission information: brill.com/authors

Titles published by Brill | Fink, Brill | mentis or Brill | Schöningh: +49(o)71 5413279216 | brill@brocom.de 